\title{
ARTUR AZEVEDO E A IDENTIDADE NACIONAL BRASILEIRA NA PASSAGEM DO SÉCULO XIX PARA O XX
}

Fernanda Cássia dos Santos Orientação: Andréa Doré

PALAVRAS-CHAVE: identidade nacional brasileira, teatro cômico, Artur Azevedo.

Preocupação constante por parte dos artistas e intelectuais brasileiros durante o século XIX, pensar a nacionalidade brasileira se constituiu numa necessidade real e da qual dependia a consolidação definitiva do Estado, pois uma unidade política, para existir, precisa de uma justificativa afetiva, o que só é conseguido através do estabelecimento de uma nação que em última instância se constitui, como afirma Eric Hobsbawm, num conjunto de tradições inventadas, e mais do que isso: a crença nelas.

No início do século XIX, buscou-se a definição daquele que seria o mito fundador do Brasil e a partir do estabelecimento da República passou-se a buscar uma representação possível pra o homem brasileiro nas produções intelectuais, artísticas e literárias. Pode-se dizer que:

A partir da década de 1870, surge então um problema: a nação deve conhecer seu povo, porque o próprio princípio Republicano, que se espraiava pela sociedade, procurava instalar um governo e em nome do povo. Pensar a Identidade e a Nação significava também pensar o povo. ${ }^{2}$

A arte, de modo geral, era considerada naquele momento um recurso pedagógico empenhado em explicar o que era o povo e qual

${ }^{1}$ HOBSBAWN, Eric, RANGER, Terence. A invenção das tradições. Rio de Janeiro: Paz e Terra, 1984, p.1.

${ }^{2}$ SOUZA, Iara Lis Stto Carvalho. Sobre o tipo popular - imagens do (s) brasileiro (s) na virada do século. In: SEIXAS, Jacy, BRESCIANI, Maria Stella e BREPOHL, Marion (orgs). Razão e Paixão na Política. Brasília: Editora Universidade de Brasília, 2002. p. 115. 
a natureza do momento histórico em que esse povo vivia. Nesse contexto, homens de letras, assim como Artur Azevedo, dedicaramse a conhecer a nação e o próprio povo brasileiro, a fim de poder desvendá-lo, diagnosticando e projetando um futuro para a nação, que em si mesma, era vista como algo que ainda estava por vir.

Artur Azevedo foi o principal autor vinculado ao teatro no período. Nascido em São Luís, no Maranhão em 1855, mudou-se para o Rio de Janeiro em 1875, depois de ter perdido o emprego de amanuense (copista de textos à mão) por ter escrito uma série de poemas satíricos sobre as pessoas de São Luis. Viveu no Rio de Janeiro até a sua morte em 1908, tendo se dedicado intensamente ao teatro. Ao longo de sua carreira, escreveu inúmeras peças distribuídas dentre os mais diversos gêneros, alcançando sucesso por suas comédias de costumes e revistas de ano. Escreveu, ainda, para a imprensa, tendo diversas crônicas e textos de crítica teatral publicados em diferentes jornais especialmente no $A$ Notícia, no qual trabalhou por muitos anos. Na academia brasileira de letras, ocupou a cadeira de número vinte e nove, que tem como fundador Martins Pena.

Para falar a respeito de Artur Azevedo é preciso compreender um pouco da situação das artes teatrais na virada do século XIX para o XX. Se na visão da crítica os autores vinculados à literatura foram capazes de escrever algo significativo a respeito da identidade nacional brasileira no período do Romantismo, uma vez que se produziu uma primeira imagem do que seria o brasileiro, o teatro não obteve o mesmo sucesso. Não houve um movimento coeso que se pudesse intitular romântico e tampouco que fosse capaz de conciliar a estrutura estética desejável com uma temática de cunho nacional. ${ }^{3}$ Em decorrência disto, a crítica teatral em inúmeras oportunidades demonstrou o seu desagrado diante da situação do teatro brasileiro de então. Efetivamente, no entanto, apenas a comédia de costumes mostrou-se capaz de trazer elementos de brasilidade da forma como

${ }^{3}$ FARIA, João Roberto. Idéias Teatrais: o século XIX no Brasil. São Paulo: Perspectiva, 2001. p. 78. 
desejavam nossos críticos, mas se tratava de um gênero menor, incapaz de atender às expectativas estéticas da crítica teatral do período.

O desconforto dos críticos, portanto, não era propriamente com o conteúdo das peças teatrais que então eram produzidas, mas com o gênero cômico. Mesmo dentre os comediógrafos do período, havia a crença de que o termo "arte dramática" designava apenas a alta dramaturgia, compreendida como a tragédia neoclássica, de modo que a comédia e seus congêneres populares estaria automaticamente excluída dessa definição. ${ }^{4}$ Mesmo antes do período republicano, a opinião da elite intelectual negou constantemente a existência de um teatro de características populares e no qual a maior parte da população brasileira via expressos seus desejos e vivências e que portanto, estava mais próximo daquilo que se podia compreender como o povo brasileiro, para o qual os autores do período voltavam os olhos em função da necessidade de estabelecer uma definição da nossa identidade.

Minha pesquisa, nesse sentido, se iniciou com a proposta de realizar uma leitura de três peças de Artur Azevedo, observando o modo como a discussão sobre a identidade nacional brasileira está expressa nessa produção. Essas peças foram selecionadas pelo seu gênero (uma vez que são as únicas burletas ${ }^{5}$ escritas pelo autor) e também pelo fato de que são textos que até então não tinham sido analisados por historiadores. São elas: A Capital Federal (1897), cujo texto se desenvolve em torno da vinda de uma família do interior de Minas para o Rio de Janeiro, trazendo uma reflexão a respeito das diferenças entre a vida da cidade e a vida no campo, $O$ Mambembe (1904), na qual o autor discute a situação do próprio teatro de sua época através da história de um grupo de teatro itinerante que apresenta espetáculos no interior do Brasil e $O$ Cordão (1908), em que é colocada a questão da repressão aos populares

4 BRAGA, Claudia. Em busca da Brasilidade: teatro brasileiro na primeira república. São Paulo: Perspectiva, 2003. p.29.

${ }^{5}$ Burleta é uma comédia de costumes acompanhada por números musicais. 
cordões carnavalescos que ocorriam no Rio de Janeiro. Como fontes auxiliares, necessárias para compreender a relação entre a crítica teatral da época com a produção do autor, selecionamos o ensaio Notícia da atual literatura brasileira - Instinto de Nacionalidade, da autoria de Machado de Assis e publicado em 1973 na revista norteamericana $O$ Novo Mundo; além de dois textos do próprio Artur Azevedo, em que ele defende suas opções estéticas.

Homem de seu tempo e também preocupado com a qualidade do teatro nacional, Artur Azevedo assumiu um compromisso com seu público, antes de tudo e assim ele justifica sua escolha pelas comédias, em particular:

[...] todas as vezes que tentei fazer teatro sério, em paga só recebi censuras, ápodos, injustiças e tudo isso a seco; ao passo, que enveredando pela bombachata, não me faltaram nunca elogios, festas, aplausos e proventos. Relevem-me citar esta última fórmula de glória, mas - que diabo! ela é essencial para um pai de família de vive da pena!. ${ }^{6}$

Ainda que aparentemente o autor tenha acreditado na negação da qualidade de suas peças por parte da crítica do período, observamos em suas comédias uma produção tipicamente brasileira. Neste sentido, acreditamos que a teoria do expressionismo ${ }^{7}$ produzida por Herder, filósofo alemão do final do século XVIII, explica a relação entre o texto de Artur Azevedo e o seu contexto social. Em linhas gerais, trata-se de uma forma de leitura de textos literários baseada na idéia de que as atividades humanas em geral, e a arte em particular, expressam a personalidade completa do indivíduo e do grupo social em que foram produzidas. Isso quer dizer que toda e qualquer obra humana está necessariamente vinculada a seu criador e também a seu povo e assim sendo, através da expressão artística, têm-se o acesso ao modo de pensar de cada grupo social, seus desejos e necessidades. É importante dizer que para Herder, o

\footnotetext{
${ }^{6}$ AZEVEDO, Artur. Em Defesa. In.: O País. Rio de Janeiro, 16 de maio de 1904. Transcrito por FARIA, João Roberto, op. cit., p. 608.

${ }^{7}$ Termo cunhado por Isaiah Berlin em seu livro: Vico e Herder. Brasília: Editora da UnB, 1982.
} 
processo ocorre de forma natural, ainda que não haja a intenção do autor. É neste ponto que há uma relação possível entre esse ideário e as comédias de Artur Azevedo, pois nelas estão expressos os costumes, as pessoas e o pensamento de seu tempo, ainda que não possamos afirmar que tenha existido alguma intenção do autor em fazê-lo. As idéias de Herder vêm sendo retomadas atualmente por Stephen Greenblatt, que ao investigar as complexas relações entre a obra literária e seu autor, afirma que a arte é capaz de ressoar o seu momento histórico, chamando a atenção para o fato de que é preciso localizá-la no seu tempo, pois sua viabilização não depende apenas da genialidade de seu autor, mas de condições históricas.

Outra via de interpretação possível para a obra de Artur Azevedo encontra respaldo nas afirmações de Elias Thomé Saliba relacionadas ao humor, que segundo o autor, participa ativamente do processo de criação da imaginação nacional construindo tipos visuais e verbais e criando estereótipos que confluem para a formação do que se poderia compreender no momento como uma imagem do homem brasileiro. Com esse referencial teórico, o trabalho de monografia foi divido fundamentalmente em três partes, sendo que na primeira investigamos a relação entre a crítica teatral do período e a busca por uma identidade nacional brasileira; na segunda discorremos a respeito do gênero cômico e da sua relação com a construção de discursos identitários; e por fim, fizemos a análise das peças teatrais com base nas questões já referidas.

A análise das fontes em conjunto com a leitura da bibliografia existente sobre o tema demonstrou que falar a respeito do povo e de sua identidade nesse período mostrava-se uma tarefa difícil diante do crescente número de estrangeiros no país e do sentimento de recalque por causa da presença maciça do elemento negro, então visto como inferior ao branco. Cada vez mais o Brasil se mostrava como o domínio do diverso, das diferenças de classe, de regiões, de costumes, de aparência e de falares. Artur Azevedo em suas peças penetrou nessa diversidade, colocando em cena nas suas peças homens humildes e homens letrados, negros, mulatos, caipiras. 
Diante dessa realidade, o autor escreveu sobre o deslumbramento da modernização da cidade do Rio de Janeiro e sobre os seus problemas sociais, sobre as diferenças cada vez maiores entre cidade e campo e sobre o abismo que dividia a elite e o povo.

Através do humor, observamos em seu texto, a crítica de alguns costumes voltados para a busca da civilidade à maneira européia (tais como a fala afrancesada que era vista como símbolo de status) numa intenção clara de chamar a atenção para o interior do país e para a necessidade de definição de uma identidade nacional própria para o Brasil. 